\title{
AN EXPERIMENTAL STUDY ON THE EFFECT OF SURFACE TEXTURE ON CONTACT STIFFNESS USING SOFT MATERIAL
}

\author{
Z. Fuadi \\ Center for Applied Acoustic, Thermal, and Vibration Studies, \\ LPPM Syiah Kuala University \\ Gedung Fakultas Teknik Universitas Syiah Kuala Lt. 1 \\ Jl. Tgk. Tanoh Abee Darussalam Banda Aceh 23111 INDONESIA \\ *Email: zahrul.fuadi@unsyiah.ac.id
}

\begin{abstract}
Contact interface is one of the most important factors in a mechanical contact because it is the place where friction, sound, and heat originate. It is therefore inevitable that modeling various phenomenon related to contact dynamics requires a proper representation of the contact interfaces. One of the methods in representing the behavior of two surfaces in contact is by using the parameter of contact stiffness. In this study, the effect of surface texture on contact stiffness is analyzed. The texture was used in order to reduce the randomness of surface roughness. The soft material was chosen to achieve a pure elastic contact thus preventing plastic deformation to the asperities. The analysis was conducted by using an indentation method employing a steel ball with a relatively small indentation force. The result show contact stiffness values of the textured surfaces were smaller than that of smooth surface. This is particularly observed at low normal load at which total deformation of the surface is relatively small compared to the asperities height. This decrease in the contact stiffness value of the textured surfaces can be related to the reduction in the real contact area.
\end{abstract}

Keywords: contact stiffness, surface texture, soft material.

\section{INTRODUCTION}

The behavior of a mechanical contact interface is highly complex because it involves complex interaction among surface asperities influenced by various factors such as asperity size, shape, elastic properties, applied load, and the presence of lubricant at the interfaces. One of the parameters that incorporates most of the factors in a quantitative representation of a contact interface is the contact stiffness. The parameter has been incorporated in various analysis of dynamic problems such as brake noises $[1,2,3,4,5]$ and other dynamic instability problems.

Among the factors affecting contact stiffness is the surface roughness, a parameter decided by the asperity size, spacing, and pattern. In a rough surface, the asperity size, spacing, and pattern are highly random so that there is no single parameter that can be used to quantify a surface roughness perfectly. Parameters such as arithmetic average of roughness profile Ra, Root Mean Square (RMS) of surface measured peaks and valleys, and the standard deviation of asperity height $\sigma$ are among the parameters that are commonly used to represent a surface properties. The latter parameter has been incorporate in the theoretical estimation of the contact stiffness value of a contact interface [4] 
Even though the contact stiffness parameter has been used in assessing various dynamic problems, the measurement of contact stiffness value of a contact interface is still difficult. Various methods have been proposed to experimentally measure the contact stiffness $[6,7,8]$. The real contact area, which is represented by the numbers of asperities in contact, is proportionally related to the contact stiffness value [6].

In this paper, the effect of surface texture on the quantitative value of normal contact stiffness is discussed. The contact stiffness value was assessed experimentally by using an indentation of a steel ball on a textured soft material surface. The effect of asperity height and spacing on the contact stiffness is highlighted.

\section{METHODOLOGY}

The contact stiffness, $K_{c}$, resulting from the interaction of the two planes is defined as the load, $W$, necessary to produce a unit displacement, $d$, of the mean separation and can be written as:

$$
K_{c}=\frac{\delta W}{\delta d}
$$

The load $W$ is defined by:

$$
W=\frac{1}{2 \sqrt{\pi}} E(\sigma / \beta)^{1 / 2} A
$$

in which $E$ is the Young's modulus of the material, $A$ is the contact area, $\beta$ is the radius of curvature of asperity height, and $\sigma$ is the standard deviation of asperity height. In a rough surface, the parameter of $\beta$ and $\sigma$ are highly random. The effect of parameter $A$ and $\sigma$ to the contact stiffness can be evaluated experimentally by using a surface with a relatively uniform contact asperities; surface texture. In order to find out the effect of those parameters on contact stiffness, various surfaces with different texture were prepared. In order to have a pure elastic contact, the soft material was used.

\section{Surface Preparation}

Four type of surfaces with different texture characteristics were prepared in this analysis. The profile of each surface is given in Figure 1. Each surface is marked as Snumber i.e. S1, S2, S3, and S4. The surfaces were prepared by casting the silicon on copper surfaces with different textures, which were manufactured beforehand. Surface S1 (Figure 1a) was prepared by casting the silicon on a smooth copper surface. Surfaces S2, S3, and S4 were prepared by casting the silicon on the textured copper surfaces which were manufactured by scratching of a diamond pin with different spacing and depth. The surface S2 has an average asperity height of $15 \mu \mathrm{m}$ and average asperity spacing of $0.07 \mathrm{~mm}$. The surface S3 has an average asperity height of $20 \mu \mathrm{m}$ and average asperity spacing of $0.14 \mathrm{~mm}$ while the surface S4 has an average asperity height of $40 \mu \mathrm{m}$ and average asperity spacing of $0.25 \mathrm{~mm}$. 
Since the surfaces are made of similar material, they have a similar modulus of elasticity of $3 \mathrm{MPa}$. The surface will be made in contact with a steel ball having diameter of $2 \mathrm{~mm}$. Thus, it is expected that the number of asperities in contact with the ball is different for each surface because of different asperity spacing. Thus, the change in contact stiffness values can be related to the number of asperity in contact and/or the real contact area.

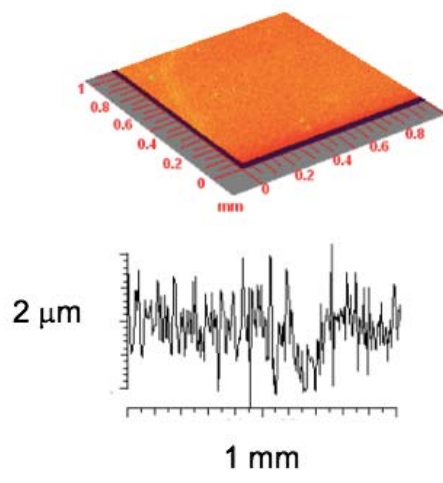

(a)
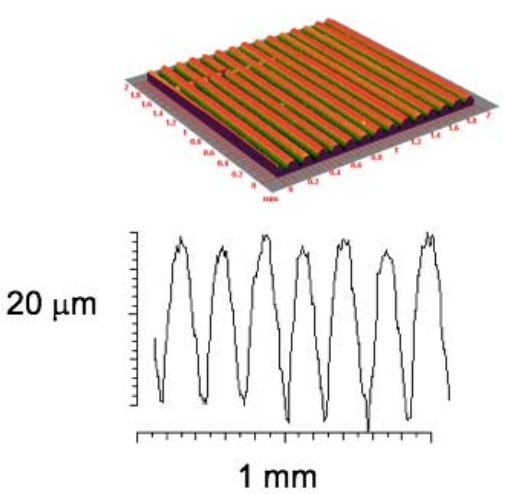

(c)

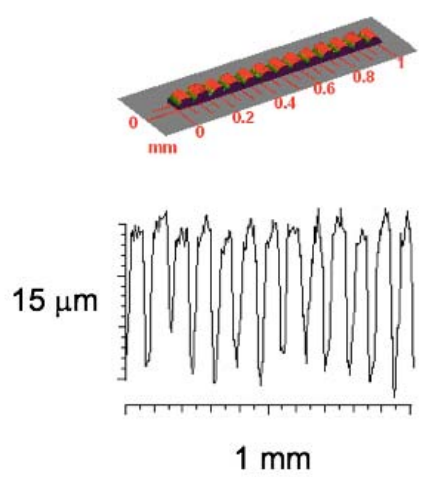

(b)
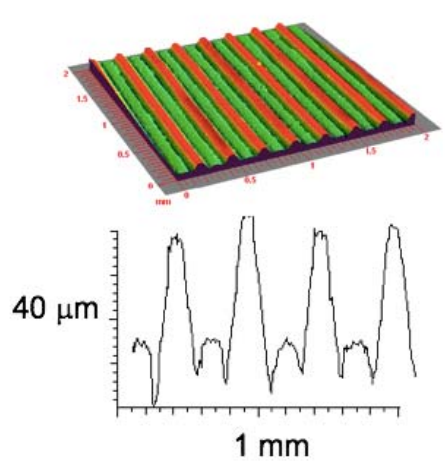

(d)

Figure 1. Profiles of surfaces used in this analysis; (a) surface S1, (b) surface S2, (c) surface S3, and (d) surface S4

\section{Experimental Setup}

The contact stiffness value was evaluated by using an indentation mechanism illustrated in Figure 2. The indenter ball has a diameter of $2 \mathrm{~mm}$. A force is applied in normal direction so that the ball is in contact with the surface. A representative graph of an indentation is given in Figure 3. In the figure, a normal force of $12 \mathrm{mN}$ was applied on the indenter resulting in the displacement of about $45 \mu \mathrm{m}$. Using the hysteresis data, the contact stiffness, $\mathrm{Kn}$, is calculated as the ratio of force, $\partial F$, to displacement, $\partial x$, at the linear region as illustrated by Figure 3 . Silicon material was used because it is highly elastic as well as to avoid plastic deformation. 

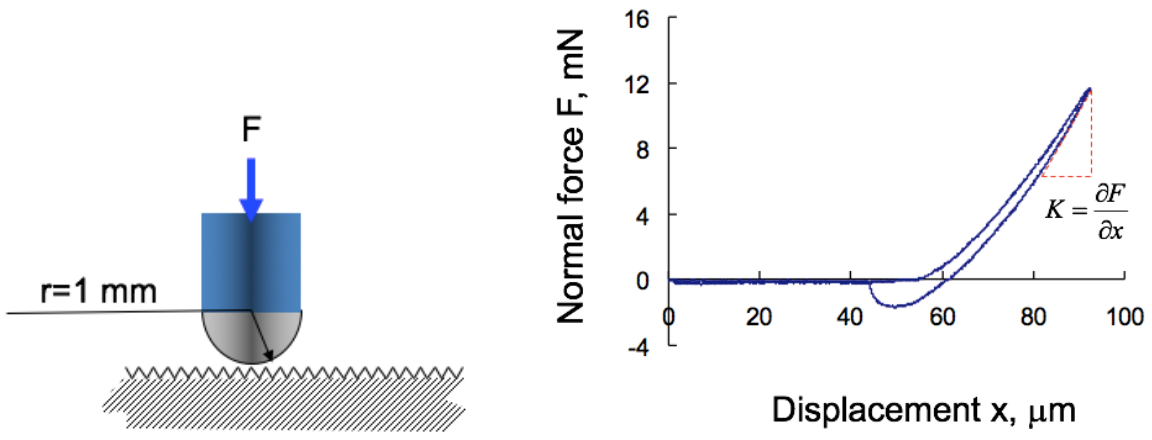

Figure 2. (a) Schematic illustration of the indentation and (b) an indentation graph

\section{RESULTS AND DISCUSSION}

Figure 3 shows the relationship among the normal force, $\mathrm{mN}$, the Hertzian contact area, $\mathrm{m}^{3}$, and the contact stiffness, $\mathrm{N} / \mathrm{m}^{2}$, for surface $\mathrm{S} 1$. It is shown in the figure that both the contact stiffness and the contact area increase as the effect of normal force increase. The indentation tests were conducted for the normal force of $30 \mathrm{mN}, 60 \mathrm{mN}$, and $100 \mathrm{mN}$. At normal force of $30 \mathrm{mN}$, the contact area was $2.79 \times 10^{-4} \mathrm{~m}^{3}$, corresponding to the contact stiffness value of $859 \mathrm{~N} / \mathrm{m}$. The contact area increases to $4.61 \times 10^{-4} \mathrm{~m}^{3}$ at normal force of $100 \mathrm{mN}$ resulting in the contact stiffness value of 1080 $\mathrm{N} / \mathrm{m}$. In this case, it seems that the contact area is linearly increases with the normal force but the contact stiffness is exponentially increases with the normal force increase.

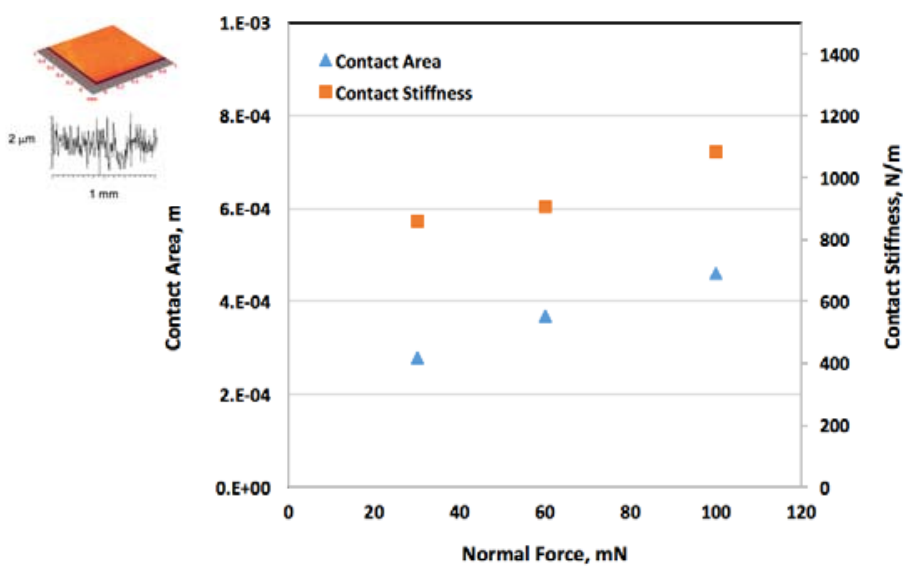

Figure 3. Relationship among the normal force, $\mathrm{N}$, the Hertzian contact area, $\mathrm{m}^{3}$, and contact stiffness, $\mathrm{N} / \mathrm{m}$ of surface $\mathrm{S} 1$

Figure 4(a) shows the relationship among the normal force, $\mathrm{mN}$, and the Hertzian contact area, $\mathrm{m}^{3}$, of all evaluated surfaces. Since this value is calculated theoretically, there is no significant differences among the value of contact area of the evaluated surfaces. There is no difference between the contact area of the smooth surface and that of the textured surface for a similar normal force. For the normal force 
of $30 \mathrm{mN}$, the Hertzian contact area is about $0.0003 \mathrm{~mm}^{3}$. The contact area increases to about $0.00046 \mathrm{~mm}^{3}$ at normal force $100 \mathrm{mN}$.

However, the value of contact stiffness for each surface were different, as shown in Figure 4(b). At normal force of $30 \mathrm{mN}$, surface $\mathrm{S} 1$ has the highest value of contact stiffness, i.e. $859 \mathrm{~N} / \mathrm{m}$. The contact stiffness value of surfaces S2, S3, and S4 are 581 $\mathrm{N} / \mathrm{m}, 493 \mathrm{~N} / \mathrm{m}$, and $586 \mathrm{~N} / \mathrm{m}$, respectively. This indicates that the contact stiffness is significantly affected by the surface texture

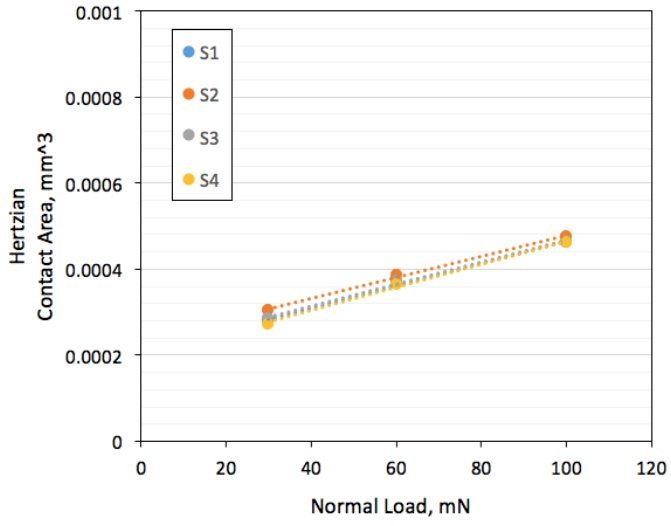

(a)

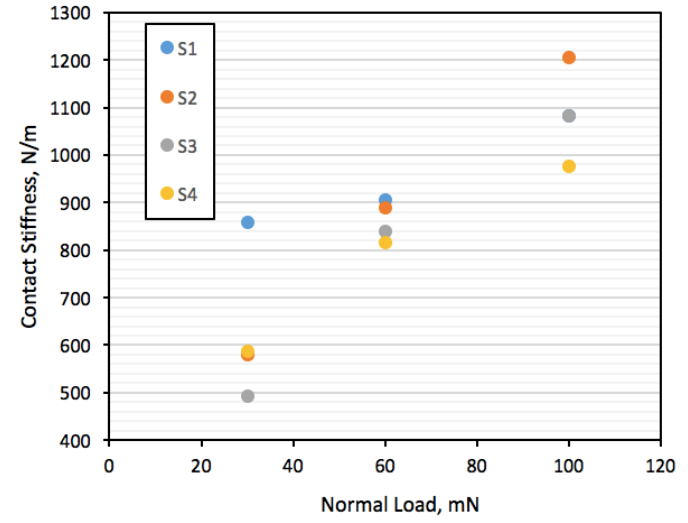

(b)

Figure 4. (a) Relationship between the normal load, mN, and the Hertzian contact area, $\mathrm{m}^{3}$, and (b) contact stiffness, $\mathrm{N} / \mathrm{m}^{2}$.

At normal force of $60 \mathrm{mN}$, the highest value of contact stiffness was for the surface S1 with a value of $906 \mathrm{~N} / \mathrm{m}$ followed by that of surface S2 with a value of 890 $\mathrm{N} / \mathrm{m}$. The contact stiffness value for those of surface S3 and S4 are $839 \mathrm{~N} / \mathrm{m}$ and 815 $\mathrm{N} / \mathrm{m}$, respectively. At the normal force of $60 \mathrm{~N}$, the range of contact stiffness value for the tested surfaces is smaller than that at the $30 \mathrm{~N}$. The highest value was achieved for the smooth surface thus indicating some effects of surface texture on the contact stiffness.

However, at the value of normal force $100 \mathrm{mN}$, the effect of surface texture on contact stiffness is less observable. At this point, the highest value of contact stiffness was achieved for surface S2 with a value of $1200 \mathrm{~N} / \mathrm{m}$. Surface S1 and S3 have a similar value of contact stiffness, i.e $1080 \mathrm{~N} / \mathrm{m}$ while surface S4 has a contact stiffness value of $976 \mathrm{~N} / \mathrm{m}$. This is presumable due to high deformation during the indentation, as shown in Figure 5. At $100 \mathrm{mN}$ the normal force caused a deformation more than 100 $\mu \mathrm{m}$ to the tested surfaces. This deformation is far larger than the height of the surface asperities as indicated in Figure 1. Nevertheless, the lowest value of contact stiffness was achieved for surface S4; the one that has the largest value of asperity height and spacing. This indicates the effects of asperity height and spacing parameters on the contact stiffness. In the future, it is interesting to analyze the quantitative relationship among these parameters on the contact stiffness.

The effect of surface texture on contact stiffness is summarized in Figure 6. The effect can be clearly observed at the normal force of $30 \mathrm{mN}$. At this force, the average deformation of the surface due to indentation force is $30 \mu \mathrm{m}$. With this value of deformation, it can be seen that surface S1 had the largest real contact area compared to 
other surfaces. Therefore, the decrease of contact stiffness value of surface S2, S3, and S3 can be related to the decrease of the real contact area, as shown in ref. [6].

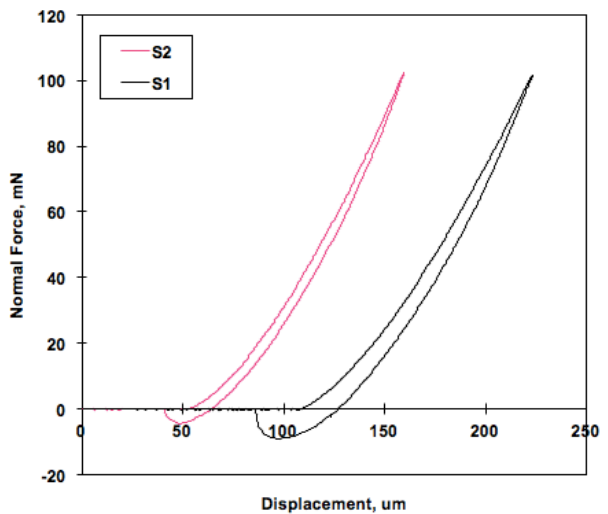

Figure 3 Representative results of the indentation tests

The effect of surface texture, asperity height and spacing, was less observable at normal force of $60 \mathrm{mN}$. At this normal force, the indentation caused deformation of more than $60 \mu \mathrm{m}$, which is larger than the highest value of asperity height of surface S4. The values contact stiffness were relatively similar for all surfaces, ranging from 815 $\mathrm{N} / \mathrm{m}$ to $906 \mathrm{~N} / \mathrm{m}$. At this condition, it is presumable that the real contact area for all surfaces subjected to indentation were similar.

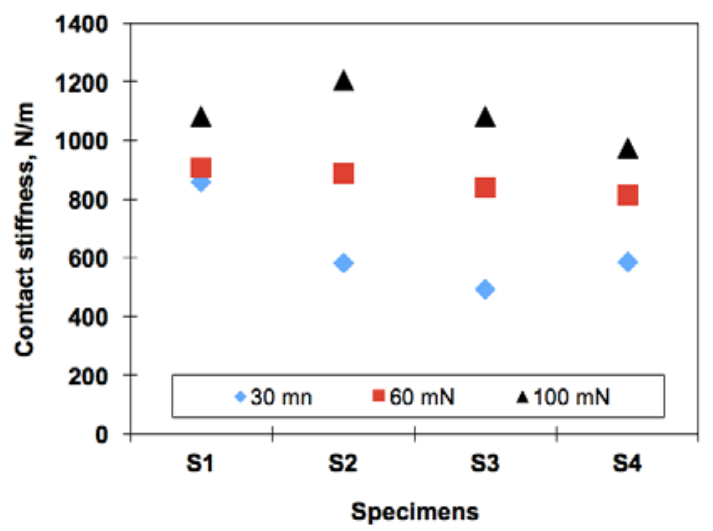

Figure 6 Effect of surface texture on the contact stiffness

A relatively similar condition was achieved for the indentation force of $100 \mathrm{mN}$, which resulted in surface deformation of more than $100 \mu \mathrm{m}$. In this condition, it seems there is another factor affecting the contact stiffness beside the real contact area. Further study is required to clarify this phenomenon.

It has been shown in previous studies that a contact interface having lower value of contact stiffness is less prone to stick-slip vibration. In this analysis, it is shown that a lower value of contact stiffness can be effectively achieved by reducing the real contact area, which is obtained by surface texturing. 


\section{CONCLUSION}

An experimental analysis on the effect of surface texture on normal contact stiffness using soft material has been conducted. It is found that the values of contact stiffness for textured surface were smaller than that of smooth surface. It seems that the surface texture caused a reduction in the real contact area. This is particularly observed at low normal load at which total deformation of the surface is relatively small compared to the average asperities height. At higher value of normal load where surface deformation is larger than the asperity height, the effect of texture on normal contact stiffness was less significant. Further study is required to clarify the phenomenon,

\section{REFERENCES}

[1] K. Popp. Some model problems showing stick-slip motion and chaos, frictioninduced vibration, chatter, squeal and chaos, (Ibrahim R. A. and Soom, A. ed), ASME, (1992) 1-12.

[2] W. W. Twordzydlo, E. E. Becker, J. T. Oden. Numerical modeling of frictioninduced vibration and dynamic instabilities, friction-induced vibration, chatter, squeal and chaos, (Ibrahim R. A. and Soom, A. ed), ASME, (1992) 87-97.

[3] Z. Fuadi, K. Adachi, H. Ikeda, H. Naito, K. Kato. Effect of Contact Stiffness on Creep-Groan Occurrence on a Simple Caliper-Slider Experimental Model. Tribol Lett (2009) 33: 169

[4] Z. Fuadi, S. Maegawa, K. Nakano, K. Adachi. Map of low-frequency stick-slip of a creep groan. Proceedings of the Institution of Mechanical Engineers, Part J: Journal of Engineering Tribology Vol 224, Issue 12, pp. 1235 - 1246, 2010

[5] Z. Fuadi. Analysis of Vibration Generated by the Rubbing of Flat Surfaces. Makara Journal of Technology, 18, 3, pp. 115-120, 2015

[6] Z. Fuadi, T. Takagi, H. Miki, K. Adachi. An experimental method for tangential contact stiffness evaluation of contact interfaces with controlled contact asperities. Proceedings of the Institution of Mechanical Engineers, Part J: Journal of Engineering Tribology. Vol 227, Issue 10, pp. 1117 - 1128

[7] M. Eriten, C. H. Lee, A. A. Polycarpou, Measurements of tangential stiffness and damping of mechanical joints: Direct versus indirect contact resonance methods, Tribology International, Volume 50, 2012, Pages 35-44,

[8] S. Medina, D. Nowell, D. Dini. Analytical and Numerical Models for Tangential Stiffness of Rough Elastic Contacts. Tribology Letters. 2013;49:103-15.

[9] Z. Fuadi, H. Zahouani, T. Takagi, H. Miki. IOP Conference Series: Materials Science and Engineering 352 (1) pp. 012009 